DOI:10.2478/rrlm-2019-0014

\title{
Point-of-care testing in diabetes management
}

\author{
Angela Cozma ${ }^{1}$, Camelia Vonica ${ }^{2}$, Adela Sitar-Taut ${ }^{1}$, Adriana Fodor $^{3 *}$ \\ 1. University of Medicine and Pharmacy "Iuliu Hatieganu" Cluj-Napoca, 4thInternal Medicine \\ Department, Cluj-Napoca, Romania \\ 2. University of Medicine and Pharmacy "Iuliu Hatieganu", Cluj-Napoca \\ 3. University of Medicine and Pharmacy "Iuliu Hatieganu" Cluj-Napoca, Clinical Center of Diabetes, \\ Nutrition and Metabolic Diseases
}

\begin{abstract}
The prevalence of diabetes mellitus (DM) has rapidly increased over the last decades, reaching epidemic magnitudes, particularly in low-and middle-income countries. Point-of-care (POC) technology enables decision making near or at the site of patient care. Portable blood glucose meters and HbAlc testing are used by the healthcare provider and millions of patients with diabetes to monitor the safety and effectiveness of the diabetes treatment. However, POC capillary blood glucose and POC HbAlc testing are not recommended for diabetes diagnosis. Rather, they have been used for screening diabetes in low-and middle-income countries to decrease the disease burden.
\end{abstract}

Keywords: point-of-care, advanced medicine, monitoring systems, bedside testing

Received: $8^{\text {th }}$ November 2018; Accepted: $28^{\text {th }}$ January 2019; Published: $8^{\text {th }}$ February 2019

\section{Introduction}

According to The International Diabetes Federation, 425 million adults had diabetes in 2017 , and the figure is expected to reach 629 million in 2045 (1).

Diabetes is diagnosed based on plasma glucose levels (either fasting plasma glucose $\geq 126$ $\mathrm{mg} / \mathrm{dL}$ or a 2 -h plasma glucose value during a 75 -g oral glucose tolerance test $\geq 200 \mathrm{mg} / \mathrm{dL}$ ) or $\mathrm{HbA} 1 \mathrm{C} \geq 6.5 \%$ (2).

Glycated hemoglobin (HbA1c) is a form of hemoglobin produced in a non-enzymatic glycation pathway by hemoglobin exposure to plasma glucose. It reflects average blood glucose levels over the past 3 months and has a strong predictive value for diabetes complications (3, 4). Monitoring HbAlc levels in patients with diabetes has been used as an indirect measure of average glycemia in several landmark studies of diabetes therapy $(3,4)$. HbA1c testing is performed routinely in all patients with diabetes, along with other tools such as blood glucose monitoring, to optimize glycemic control. More recently, HbA1c measurement has been used for diagnosing prediabetes and diabetes (5). Values $\geq 5.7 \%$ define prediabetes, while values $\geq 6.5 \%$ are characteristic of diabetes.

POC or bedside testing is known as medical diagnostic testing that provides immediate re-

\footnotetext{
*Corresponding author: Adriana Fodor, University of Medicine and Pharmacy "Iuliu Hatieganu" Cluj-Napoca. E-mail: adifodor@yahoo.com
} 
sults using transportable instruments or test kits, performed by clinical staff without laboratory training. It also includes patient self-monitoring. Today, cheaper, faster and reliable POC testing instruments offer onsite results that reduce the time spent with classic laboratory measures (6).

\section{POC blood glucose monitoring test in diabetes management}

Early detection and intervention is crucial in diabetes management. Lifestyle interventions reverse prediabetes and result in a reduction of diabetes incidence over more than ten years (7). The benefits of achieving early glycemic control in the natural history of diabetes are important: every $1 \%$ reduction in $\mathrm{HbA} 1 \mathrm{c}$ results in a $37 \%$ reduction in microvascular complications, a $43 \%$ reduction in amputations, a $21 \%$ reduction in death from peripheral vascular disease, and a $14 \%$ reduction in myocardial infarctions (4).

Diabetes and prediabetes may be screened and diagnosed based on the same tests: plasma glucose levels or HbA1c levels (2). Glucose levels should be assessed in plasma separated immediately after blood collection.

Glucose testing using glucose meters became a practice in the health care system around 1987 and it has been perfected from $1.2 \mathrm{~kg}$ instruments to light weight pocket-size devices. POC capillary blood glucose testing is currently used by health care providers and millions of diabetic patients. However, POC blood glucose testing is not recommended for diabetes diagnosis. Rather, it has been used for screening diabetes in lowand middle-income countries to decrease the disease burden (8).

Self-monitoring blood glucose (SMBG) is intended especially for patients that use multiple insulin injections per day or insulin pumps for diabetes treatment. Patients should monitor their glycemic value before every meal or snack, from time to time in postprandial state, during the night, when symptoms of hypoglycemia appear, and after they correct it, before driving, before and during exercising. Glycemic values can be determined up to 6-10 times per day (9). The benefit of structured SMBG in the management of insulin treated patients is well-established (10). Moreover, regular SMBG use in non-insulin treated patients also has a favorable impact on glycemic control $(11,12)$.

It is very important for SMBG to be integrated in an educational plan, in order to get benefit from it. One in 6 patients on oral medication who practise SMBG neither use the results, nor tell their doctor about them (13). These findings demonstrate that glucose monitoring is a tool that helps to monitor diabetes status, facilitates management interventions (lifestyle changes, pharmacotherapy), but cannot be used without educational support.

In hospital settings, the standard glucose determination remains the central laboratory value. However, POC blood glucose measurement is now the standard bedside glucose monitoring technique in a variety of clinical settings including acute and chronic care facilities, general hospital wards and intensive care units, physicians' offices, nursing homes and assisted living facilities (14). In health care settings, patients have to be monitored before every meal or every $4-6 \mathrm{~h}$ if they do not receive nutrition. The frequency of blood glucose monitoring increases in patients on intravenous insulin infusion, ranging from every 30 min to every $2 \mathrm{~h}(9)$.

For adequate monitoring and therapeutic adjustments, SMBGs should provide accurate and reliable measurements. In the European Union, SMBGs that are intended to be used by patients with diabetes should meet the standard of the International Organization for Standardization (ISO) 15197, revised in 2013 (15). The evaluation of analytical performance according to ISO 15197 includes: evaluation of measurement precision, evaluation of system accuracy, eval- 
uation of influence quantities (hematocrit and interfering substances such as medications), and evaluation of the stability of reagents and materials. According to the ISO 15197 minimum accuracy criteria, at least $95 \%$ of measurement results should fall within $\pm 15 \mathrm{mg} / \mathrm{dl}$ of the reference value at $\mathrm{BG}$ concentrations $<100 \mathrm{mg} / \mathrm{dl}$ and within $\pm 15 \%$ at $\mathrm{BG}$ concentrations $\geq 100$ $\mathrm{mg} / \mathrm{dl}$. Moreover, ISO 15197 requires the accuracy evaluation of 3 different test strip lots, and each individual test strip lot must comply with the $95 \%$ accuracy criteria.

The recently revised FDA guidance (16), published in 2016, for the premarket evaluation of SMBGs differs from ISO 15197 especially regarding system accuracy evaluation (Table 1). Ninety-five percent of all SMBG results should be within $+/-15 \%$ of the laboratory-based glucose results across the entire claimed measuring range of the device, and $99 \%$ of all SMBG results should be within $+/-20 \%$ of the laboratory-based glucose results across the entire claimed measuring range of the device.

Recommended standards of blood glucose monitoring test systems (BGMSs) designed for medical care settings differ from glucose meters used by people with diabetes at home (over the counter), and separate guidance has been issued by FDA. Thus, the standards of BGMS, used by health care providers in POC testing, are: $\bullet 95 \%$ of meter values should be within $12 \%$ of the reference value for BG over $75 \mathrm{mg} / \mathrm{dl}$, and within
$12 \mathrm{mg} / \mathrm{dl}$ for BG below $75 \mathrm{mg} / \mathrm{dl}$; $98 \%$ of values should be within $15 \%$ of the reference value for BG over $75 \mathrm{mg} / \mathrm{dl}$, and within $15 \mathrm{mg} / \mathrm{dl}$ for BG below $75 \mathrm{mg} / \mathrm{dl}$ (17). BGMSs intended for prescription use in a hospital setting should be able to measure BG accurately down to $10 \mathrm{mg} /$ $\mathrm{dl}$ and up to $500 \mathrm{mg} / \mathrm{dl}$, while those intended for use outside a hospital setting should be able to measure BG accurately down to $20 \mathrm{mg} / \mathrm{dl}$ (17). In a recent study, designed to evaluate the accuracy of 17 POC glucose meters, only 2 met the ISO 2013 criteria, and the mean absolute relative differences versus reference values ranged widely from $5.6 \%$ to $20.8 \%$ (18). Moreover, the price of the glucose strips did not correlate with the accuracy of the result (18). In another recent study, assessing the accuracy of the 18 most purchased personal blood glucose meters in USA, only 6 meters met the protocol-specified accuracy standard similar to current ISO and FDA standards, while the mean absolute relative differences versus reference values ranged from $5.3 \%$ to $15.5 \%$ (19). The surveillance of post-marketing device performance should be taken into consideration in the future. Over time, analytical accuracy might no longer represent the initial accuracy of data that were submitted to the regulatory authorities. The performance of blood glucose meters diminishes over time (19). However, the POC glucose meter technology is not always the cause of inaccuracy. Additional errors can come from: temperature, humidity,

Table 1. Minimum SMBG/BGMS system accuracy criteria according to ISO 15197/2003 and FDA/2016

\begin{tabular}{|c|c|c|c|c|c|c|c|c|}
\hline \multirow[b]{2}{*}{$\%$ results } & \multirow{2}{*}{\multicolumn{2}{|c|}{$\begin{array}{c}\text { ISO } \mathbf{1 5 1 9 7 / 2 0 0 3} \\
\begin{array}{c}95 \% \text { of } \mathrm{SMBG} \\
\text { results }\end{array} \\
\end{array}$}} & \multicolumn{2}{|c|}{ FDA/2016 } & \multicolumn{4}{|c|}{ FDA/2016 } \\
\hline & & & $\begin{array}{l}95 \% \text { of } \mathrm{SMBG} \\
\text { results }\end{array}$ & $\begin{array}{c}99 \% \text { of } \mathrm{SMBG} \\
\text { results }\end{array}$ & $\begin{array}{r}95 \% \\
\mathrm{re}\end{array}$ & $\begin{array}{l}\text { BGMS } \\
\text { ults }\end{array}$ & $\begin{array}{r}98 \% \text { o } \\
\text { res }\end{array}$ & $\begin{array}{l}\text { BGMS } \\
\text { lits }\end{array}$ \\
\hline Within & $\begin{array}{c} \pm 15 \\
\mid \mathrm{mg} / \mathrm{dl}\end{array}$ & $\pm 15 \%$ & $\pm 15 \%$ & $\pm 20 \%$ & $\begin{array}{c} \pm 12 \\
\mathrm{mg} / \mathrm{dl}\end{array}$ & $\pm 12 \%$ & $\begin{array}{c} \pm 15 \\
\mathrm{mg} / \mathrm{dl}\end{array}$ & $\pm 15 \%$ \\
\hline At BG & $\begin{array}{l}<100 \\
\mathrm{mg} / \mathrm{dl}\end{array}$ & $\begin{array}{l}\geq 100 \\
\mathrm{mg} / \mathrm{dl}\end{array}$ & Entire range & Entire range & $\begin{array}{c}<75 \\
\mathrm{mg} / \mathrm{dl}\end{array}$ & $\begin{array}{c}\geq 75 \mathrm{mg} / \\
\mathrm{dl}\end{array}$ & $\begin{array}{c}<75 \\
\mathrm{mg} / \mathrm{dl}\end{array}$ & $\begin{array}{l}\geq 75 \\
\mathrm{mg} / \mathrm{dl}\end{array}$ \\
\hline
\end{tabular}


altitude, poor sampling and inappropriate strip storage and handling, patient's state or drug interference, sample sources and collection sites, interfering with the glucose meter cleaning solution or the disinfectant wipe (20). Safety standards should include interdiction of sharing lancing devices, needles or pens, to avoid the risk of blood-borne diseases (17).

Currently, POC blood glucose testing is the mainstay for monitoring and decision making in diabetes management. However, it cannot replace central laboratory testing for precision and accuracy. POC glucose meters are user friendly, with rapid turn-around times ( $<5$ minutes), require small blood samples $(0.3-1 \mu 1)$, and are cost-effective - a three times lower cost than central laboratory testing (17).

\section{POC Continuous Glucose Monitoring Systems (CGMS) in diabetes management}

Hypo- and hyperglycemia are common complications encountered in clinical care settings despite time and effort dedicated to achieving and maintaining good glycemic control. A target glucose range of $140-180 \mathrm{mg} / \mathrm{dl}$ is recommended for the majority of hospitalized patients (21). CGMS measure interstitial or venous glucose values with a frequency of 1 to 15 minutes and are closely correlated to plasma glucose values determined by central laboratories. An advantage of CGMS is represented by the alarms for either hypo- or hyperglycemia (22). Variations between interstitial and plasma values appear when there are rapid changes in plasma glucose levels. There are two types of CGMS: professional CGMS and real-time CGMS (Table 2). Professional devices are used for "blinded" or "masked" collection of glucose data. Patients wear the device for a specific time period, but only see the CGMS data after they have been analyzed by a healthcare professional. Personal
CGMS can provide near real-time glucose data (rtCGM) or intermittently viewed data (iCGM). While rtCGM sends data continuously to a receiver, iCGM does not passively capture glucose information in the absence of a scan and the wearer must scan the sensor with a handheld reader in order for the sensor to initiate the real-time glucose measurements. The only iCGM is the recently approved form of CGMS known as "flash" glucose monitoring (FreeStyle Libre; Abbott) (23)

In terms of calibration, there are two kinds of sensors: those that are calibrated in the factory without the need of user calibration, and those that need calibration using capillary glucose values.

FreeStyle Libre Flash and FreeStyle Libre Pro do not need calibration by users. The calibration process is part of the sensor manufacturing process and performed under controlled laboratory conditions (23). However, a recent head-to-head accuracy comparison between the two newly approved Abbott FreeStyle Libre and Dexcom G5 Mobile systems showed that DG5M sensor has greater accuracy across all glucose values except in hypoglycemia, while Libre's accuracy decreases between days 11 and 14 (30).

The latest-generation CGMS are more accurate and sensitive for hypoglycemia. Thus, Guardian Paradigm Veo and MiniMed 640G developed by Medtronic allow the suspension of insulin infusion during or even prior to hypoglycemia (28), while the MiniMed $670 \mathrm{G}$ system automatically adjusts basal insulin levels. This kind of therapy is known as sensor-augmented insulin pump with low glucose suspend. The real-world trial data from the first 124 patients who completed 3 months of SmartGuard Auto Mode-enabled MiniMed 670G system use have been recently published. Real-world patients used Auto Mode for a median of $80.8 \%$ of the time. The overall mean time spent in target glucose range was 66\% during baseline Manual Mode versus 
Table 2. Professional and Personal devices specifications

\begin{tabular}{|c|c|c|c|c|c|}
\hline Type of CGMS & $\begin{array}{l}\text { Accuracy } \\
(\text { MARD\%) }\end{array}$ & $\begin{array}{c}\text { Calibration } \\
\text { (n/day) }\end{array}$ & $\begin{array}{l}\text { Sensor life- } \\
\text { time (days) }\end{array}$ & $\begin{array}{c}\text { FDA } \\
\text { approval }\end{array}$ & Ref. \\
\hline \multicolumn{6}{|l|}{ Professional devices } \\
\hline Roche iPro Professional & 14.2 & 3 & 6 & 2016 & {$[23]$} \\
\hline Abbott FreeStyle Libre Pro & 12,1 & No & 14 & 2016 & [24] \\
\hline \multicolumn{6}{|l|}{ Personal Devices } \\
\hline DexcomG4 Platinum* & $\begin{array}{l}\text { Adults: } 13 \text { Chil- } \\
\text { dren: } 15\end{array}$ & 2 & 7 & 2012 & {$[25]$} \\
\hline DexcomG5 Movile* & $\begin{array}{l}\text { Adults: } 9 \text { Chil- } \\
\text { dren: } 10\end{array}$ & 2 & 7 & 2016 & {$[26]$} \\
\hline Medtronic Paradigm Veo & 13.6 & 3 & 7 & 2006 & {$[27]$} \\
\hline $\begin{array}{l}\text { MiniMed 640G System with } \\
\text { SmartGuard }\end{array}$ & 14.2 & 3 & 7 & 2017 & {$[27]$} \\
\hline Abbott FreeStyle Libre Flash & 11.4 & No & 14 & 2018 & {$[28]$} \\
\hline FreeStyle Navigator II & 12.3 & $5 * *$ & 5 & 2011 & [29] \\
\hline
\end{tabular}

$73.3 \%$ during Auto Mode ( $<<0.001)$ (31).

Regarding long-term glycemic control, a recent study in 322 patients with T1DM showed a $0.5 \%$ reduction in $\mathrm{HbA} 1 \mathrm{c}$ in patients following an intensive insulin regimen with CGM systems compared to those following the same intensive insulin regimen with SMBG (32). Two additional clinical trials in patients with T1DM showed that using CGMS along with multiple daily injections lowered HbA1c levels by $0.43 \%$ and $0.6 \%$, respectively $(33,34)$.

Additional benefits of CGMS are reducing daily fluctuations of glucose levels. Thus, glycemic variability in type $1 \mathrm{DM}$ patients using insulin pumps and real-time glucose monitoring devices had an SD reduction from 60.74 to $51.67 \mathrm{mg} / \mathrm{dl}$ $(p=0.010)$, and AUC diminished from 41.23 to $21.22(p<0.001)(35)$. Moreover, a recent study showed that integrated pump/CGMS technology versus multiple daily injections in T1DM increases life expectancy by 3.51 years $(95 \% \mathrm{CI}$, 3.47-3.55) (36).

A recent study reported benefits of using flash CGMS even in well-controlled T1DM by reduc- ing the time spent in hypoglycemia compared to using SMBG (37). Current guidelines have no specific recommendations for patients or for clinical setting use (38). However, support in selecting appropriate system for specific patient has been issued recently (39).

Several factors such as: edema, shock state, use of vasoconstrictors affect peripheral perfusion in ICU patients and disturb the accuracy of capillary glucose measurements $(40,41)$. Moreover, glucose measurement in ICU is performed intermittently with the risk of undetected hypoglycemia, and the workload for the ICU nursing staff is considerable (42). In this respect, several studies have shown that CGMS may guide insulin treatment in critically ill patients similarly to intermittent POC measurements.

The first-generation intravenous CGMS was evaluated in a multicenter observational study, in 100 critically-ill patients (43). The authors concluded that it was easy to set up and use, attached to a peripheral venous catheter. Of the intravenous glucose monitoring measurements, 93\% met the 2003 ISO Standards for accura- 
cy. Frequent and accurate POC blood glucose testing may improve the safety and efficacy of insulin therapy and blood glucose control in hospitalized patients (43).

A randomized controlled trial compared subcutaneous CGMS with frequent POC measurements in 156 critically ill patients (42). Subcutaneous CGMS were found to be as safe and effective as intermittent POC testing and reduced nursing workload and daily costs (42).

Another study compared subcutaneous and intravenous CGMS in 15 surgical patients, in operating rooms and intensive care units (3592 comparative samples). The intravenous CGMS STG-55 (Nikkiso, Tokyo, Japan) was defined as the standard device in the study, because it had previously shown acceptable accuracy compared to the blood gas analyzer (Pearson's correlation coefficient was 0.96) (44). The study found that subcutaneous and intravenous CGMS were not highly correlated during either surgery or ICU stay. The subcutaneous CGMS iPro2 (Medtronic Japan, Tokyo, Japan) was limited in terms of utility because it could not display real-time blood glucose levels (45). However, the authors did not deny the overall accuracy of subcutaneous CGMS, suggesting that blood glucose measurement during hemodynamic or fluid instability might be suitable for intravenous CGMS, while testing after stabilization might be suitable for the subcutaneous method (45).

\section{POC HbA1c assays in diabetes management}

Diabetes and prediabetes may be screened and diagnosed based on the same tests: plasma glucose levels (discussed above) or HbAlc levels (2). The HbA1c test has several advantages compared to plasma glucose criteria, including: fasting not required, better pre-analytical stability, and less variability during stress and illness. However, the lower sensitivity of HbAlc at the cut point of $6.5 \%$, the greater cost and restricted availability of $\mathrm{HbAlc}$ testing in certain areas may offset the advantages. Moreover, it is important to take into consideration other factors that may impact hemoglobin glycation independently of glycaemia, including ethnicity, anemia, hemoglobinopathies, etc.

HbA1c testing should be performed using a method that is certified by the National Glycohemoglobin Standardization Program (NGSP) (www.ngsp.org) and standardized to the Diabetes Control and Complications Trial (DCCT) assay (2).

Although POC instruments are available for $\mathrm{HbA} 1 \mathrm{c}$ testing, there are concerns that limit their diagnostic application, such as: differences in their accuracy, testing performed by non-laboratory personnel, and lack of a proficiency testing program. Although some POC HbAlc assays may be NGSP certified, the use of POC assays for diagnostic purposes is not generally recommended (9).

Recently, some authorities approved the use of POC HbAlc testing in particular settings. The Australian Government approved the use of the $\mathrm{HbA} 1 \mathrm{c}$ test for diagnosis of the Indigenous Australian population enrolled exclusively in the QAAMS POC Testing Program. This decision was based on the consistently high analytical quality of POC HbAlc testing in QAAMS, as evidenced by the results of continuing external quality assurance and quality control testing over the past 15 years (46). DCA Vantage measured $\mathrm{HbA} 1 \mathrm{c}$ values close to $6.5 \%$ both accurately and precisely. The authors argue that POC testing devices are suitable for the diagnosis of diabetes, and each individual POC device should be assessed independently when considering its suitability for diabetes diagnosis (46).

Conversely, POC HbAlc testing may be used for screening purposes. In a recent study, dental students were effective in screening patients in a dental school clinic for prediabetes or diabetes 
by assessing conventional risk factors for diabetes, obtaining finger stick blood samples and analyzing the results with $\mathrm{HbA1c}$ test kits (47). Another recent study found that systematically screening adults (aged $\geq 45$ years) for diabetes using a POC HbAlc test vs. standard practices greatly increases the chances for a screen to occur $(\mathrm{P}=0.005)$. The authors concluded that POC HbAlc testing may be the most effective method to identify patients with unknown hyperglycemia (48).

$\mathrm{HbA} 1 \mathrm{c}$ testing should be performed routinely in all diabetic patients during continuing care to assess glycemic control. The frequency of HbA1c testing depends on the achieved levels of $\mathrm{HbA} 1 \mathrm{c}$ and their variability: at least two times a year in patients who meet treatment goals and every 3 months in patients who do not meet glycemic goals or whose therapy has changed (9). The American Diabetes Association recommends optimal $\mathrm{HbA1c}$ targets for non-pregnant adults less than $7 \%$, but each target must be individualized to the particular patient (9).

The use of POC HbAlc testing may allow more timely treatment changes during consultations. Studies have found that patients who are aware of their HbA1c level have lower measurement results than those who are unaware; the availability of immediate results motivates patients for a better glycemic control (49). Only three POC HbAlc testing instruments are available in USA, having received NGSP manufacturer certification (Table 3) (50). Currently, NGSP requires at least 37 out of 40 samples to fall within $6 \%$, making them precise and reliable for medical daily use (51). Moreover, these criteria will even be tightened starting with January 2019, as follows: 36 of 40 results within $\pm 5 \%$ (51).

POC HbAlc testing improved glycemic control by reducing $\mathrm{HbA} 1 \mathrm{c}$ by $1.03 \pm 0.33$ percentage points during a period of 12 months in a clinical practice setting (52). Moreover, using one of these devices reduces health care costs, prevents complications and can improve patient's adherence (52).

Recently, a new HbA1c analyzer for POC testing was evaluated with a comparative laboratory instrument, in China. The sensitivity and specificity of $\mathrm{HbA1c}$ EZ 2.0 in the clinical diagnosis of diabetes was evaluated in 842 subjects from Beijing. At the HbAlc cut-off value of $6.5 \%$, sen-

Table 3. POC HbA1c device features

\begin{tabular}{lccc}
\hline Characteristic & $\begin{array}{c}\text { HbA1C Now Chek } \\
\text { Diagnostics (1) }\end{array}$ & $\begin{array}{c}\text { Axis-Shield Afinion } \\
\text { Analyzer (2) }\end{array}$ & $\begin{array}{c}\text { Siemens DCA } \\
\text { Vantage (3) }\end{array}$ \\
\hline \multirow{2}{*}{ Physical size } & $\begin{array}{c}\text { Portable, handheld } \\
\text { Dim: } 6.35 / 1.0 / 5.1 \mathrm{~cm} \\
\text { Weight: } 0.18 \mathrm{~kg}\end{array}$ & $\begin{array}{c}\text { Bench-top unit } \\
\text { Dim: } 34 / 17 / 19 \mathrm{~cm} \\
\text { Weight: } 5 \mathrm{~kg}\end{array}$ & $\begin{array}{c}\text { Bench-top unit } \\
\text { Dim: } 27.7 / 25.4 / 28.7 \mathrm{~cm} \\
\text { Weight: } 3.88 \mathrm{~kg}\end{array}$ \\
\hline Sample size $(\mu \mathrm{L})$ & 5 & 1.5 & 1 \\
\hline Analysis time $(\mathrm{min})$ & 5 & 3 & 6 \\
\hline Reporting HbA1c range $(\%)$ & $4-13$ & $4-15$ & $2.5-14$ \\
\hline Other quantitative tests & & Albumin: creatinine ratio \\
& No & $\begin{array}{c}\text { Cheactive protein } \\
\text { Cholesterol } \\
\text { Creatinine }\end{array}$ & $\begin{array}{c}\text { Albumin: creatinine } \\
\text { ratio }\end{array}$ \\
& & $\begin{array}{c}\text { Microalbumin } \\
\text { Creatinine }\end{array}$ \\
\hline
\end{tabular}

Bayer Diabetes Care A1cNow Monitor package insert. Sunnyvale, Calif, Bayer HealthCare, 2008. (2) Axis-Shield Afinion package insert. Dundee, Scotland, Axis-Shield POC, 2012. (3) Siemens DCA Systems package insert. Tarrytown, N.Y., Siemens Healthcare Diagnostics, August 2008. 
sitivity and specificity were $76.1 \%$ and $86.6 \%$, while the area under ROC curve for the clinical diagnosis of diabetes was 0.911 (53).

Limitations of $\mathrm{HbA1c}$ testing

Conditions that affect red blood cell turnover (anemia, recent blood transfusion, end-stage renal disease, pregnancy, use of drugs that stimulate erythropoiesis) may result in discrepancies between the $\mathrm{HbA} 1 \mathrm{c}$ result and the patient's mean glycemia. Hemoglobin variants must be considered, particularly when the HbA1c result does not correlate with the patient's SMBG levels. Monitoring options in these cases include more frequent and/or different timing of SMBG or CGMS use. Other measures of average glycemia such as fructosamine and 1,5-anhydroglucitol are available, but their translation into average glucose levels and their prognostic significance are not as clear as for $\mathrm{HbAlc}$.

HbA1c does not provide a measure of glycemic variability or hypoglycemia. For patients prone to glycemic variability, especially patients with T1DM, glycemic control is best evaluated by the combined measurements of HbA1c and SMBG or CGMS. African Americans have higher HbA1c values compared to non-Hispanic whites for a given mean BG concentration (54).

\section{POC tests for detecting microalbuminuria}

Chronic kidney disease (CKD) is a chronic complication characterized by increased albuminuria, decreased glomerular filtration rate, or other kidney damage. The final evolution of diabetic CKD is end-stage renal disease requiring dialysis or kidney transplantation.

Screening for CKD in diabetic patients is done by measuring the albumin-creatinine ratio in spot urine collection. Measuring albumin alone, without simultaneously determining urinary creatinine, is susceptible to errors due to urine concentration variability.
The POC systems available for measuring urinary albumin and creatinine are: HemoCue ${ }^{\circledR}$ 201 urine albumin (Ängelholm, Sweden), URiSCAN 2 ACR (YD diagnostics, Yongin, Korea) and Clinitek ${ }^{\circledR}$ (Siemens ${ }^{\circledR}$ Medical Solutions Diagnostics, New York, USA). The HemoCue ${ }^{\circledR}$ system measures urine albumin quantitatively, using $18 \mu \mathrm{l}$ of urine, and displays the result in 90 seconds. URiSCAN and Clinitek ${ }^{\circledR}$ systems are semi-quantitative POC tests for urinary albumin and creatinine measurements. In a controlled randomized clinical trial including 1020 samples, URiSCAN and Clinitek ${ }^{\circledR}$ had $90.2 \%$ and $83.0 \%$ sensitivity, and $87.7 \%$ and $72.2 \%$ specificity, respectively (55).

Nonetheless, urinary albumin POC systems are useful tools that provide immediate clinical information concerning renal status in clinical care settings. Future directions involve improving sensitivity and specificity for accurate diagnostic use.

\section{Take home messages}

POC devices are useful tools in clinical care settings for screening, diagnosis and management of diabetes, due to the following advantages:

- Fast sample-to-result test;

- Low sample consumption;

- Test results comparable to central laboratory findings;

- Non- or minimally invasive samples;

- Long shelf life with extended reagent storage;

- $\quad$ Easy system operation - can be used by patients or nurses;

- Cheap and portable systems.

\section{Authors' contribution}

AC (Conceptualization; Data curation; Formal analysis; Investigation;Methodology; Project administration; Writing - original draft) CV (Data curation; Formal analysis; Investiga- 
tion; Methodology; Writing - original draft)

AST (Conceptualization; Software)

AF (Conceptualization; Methodology; Supervision; Validation; Writing - review \& editing)

Angela Cozma and Camelia Vonica have equal contribution to the paper.

\section{Conflict of interest}

None to declare.

\section{Bibliography}

1. International Diabetes Federation Diabetes Atlas, Eighth edition. 2017. http://diabetesatlas.org/resources/2017-atlas.html

2. American Diabetes Association. Classification and Diagnosis of Diabetes: Standards of Medical Care in Diabetes-2018. Diabetes Care. 2018 Jan;41(Suppl 1):S13-S27. DOI: $10.2337 / \mathrm{dc} 18-\mathrm{S} 002$

3. Albers JW, Herman WH, Pop-Busui R, Feldman EL, Martin CL, Cleary PA, et al. Effect of prior intensive insulin treatment during the Diabetes Control and Complications Trial (DCCT) on peripheral neuropathy in type 1 diabetes during the Epidemiology of Diabetes Interventions and Complications (EDIC) Study. Diabetes Care. 2010 May;33(5):1090-6. DOI: 10.2337/dc091941

4. Stratton IM, Adler AI, Neil HA, Matthews DR, Manley SE, Cull CA, et al. Association of glycaemia with macrovascular and microvascular complications of type 2 diabetes (UKPDS 35): prospective observational study. BMJ. 2000 Aug 12;321(7258):405-12. DOI: 10.1136/ bmj.321.7258.405

5. Gillett MJ. International Expert Committee report on the role of the A1c assay in the diagnosis of diabetes: Diabetes Care 2009; 32(7): 1327-1334. Clin Biochem Rev. 2009 Nov;30(4):197-200.

6. Larsson A, Greig-Pylypczuk R, Huisman A. The state of point-of-care testing: a European perspective. Ups J Med Sci. 2015 Mar;120(1):1-10. DOI: 10.3109/03009734.2015.1006347

7. Portero McLellan KC, Wyne K, Villagomez ET, Hsueh WA. Therapeutic interventions to reduce the risk of progression from prediabetes to type 2 diabetes mellitus. Ther Clin Risk Manag. 2014 10:173-88.
8. Saldarriaga EM, Vodicka E, La Rosa S, Valderrama M, Garcia PJ. Point-of-Care Testing for Anemia, Diabetes, and Hypertension: A Pharmacy-Based Model in Lima, Peru. Ann Glob Health. 2017 Mar - Apr;83(2):394-404. DOI: 10.1016/j.aogh.2017.03.514

9. American Diabetes Association. Glycemic Targets: Standards of Medical Care in Diabetes-2018. Diabetes Care. 2018 Jan;41(Suppl 1):S55-S64. DOI: 10.2337/ dc18-S006

10. Bergenstal RM, Gavin JR, 3rd, Global Consensus Conference on Glucose Monitoring P. The role of self-monitoring of blood glucose in the care of people with diabetes: report of a global consensus conference. Am J Med. 2005 Sep;118(Suppl 9A):1S-6S. DOI: 10.1016/j. amjmed.2005.07.055

11. Polonsky WH, Fisher L, Schikman CH, Hinnen DA, Parkin CG, Jelsovsky Z, et al. Structured self-monitoring of blood glucose significantly reduces A1C levels in poorly controlled, noninsulin-treated type 2 diabetes: results from the Structured Testing Program study. Diabetes Care. 2011 Feb;34(2):262-7. DOI: 10.2337/dc101732

12. Virdi N, Daskiran M, Nigam S, Kozma C, Raja P. The association of self-monitoring of blood glucose use with medication adherence and glycemic control in patients with type 2 diabetes initiating non-insulin treatment. Diabetes Technol Ther. 2012 Sep;14(9):790-8. DOI: 10.1089/dia.2012.0047

13. Grant RW, Huang ES, Wexler DJ, Laiteerapong N, Warton ME, Moffet HH, et al. Patients who self-monitor blood glucose and their unused testing results. Am J Manag Care. 2015 Feb 1;21(2):e119-29.

14. Rajendran R, Rayman G. Point-of-care blood glucose testing for diabetes care in hospitalized patients: an evidence-based review. J Diabetes Sci Technol. 2014 Nov;8(6):1081-90. DOI: 10.1177/1932296814538940

15. ISO 15197. In vitro diagnostic test systems - Requirements for blood-glucose monitoring systems for self-testing in managing diabetes mellitus. 2013. https://www.iso.org/standard/54976.html

16. Food and Drug Administration. Self-Monitoring Blood Glucose Test Systems for Over-the-Counter Use 2016. https:/www.fda.gov/downloads/MedicalDevices/DeviceRegulationandGuidance/GuidanceDocuments/ UCM380327.pdf

17. Food and Drug Administration. Blood Glucose Monitoring Test Systems for Prescription Point-of-Care Use 
2016. https://www.fda.gov/downloads/ucm380325.pdf

18. Ekhlaspour L, Mondesir D, Lautsch N, Balliro C, Hillard M, Magyar K, et al. Comparative Accuracy of 17 Pointof-Care Glucose Meters. J Diabetes Sci Technol. 2017 May;11(3):558-66. DOI: 10.1177/1932296816672237

19. Klonoff DC, Parkes JL, Kovatchev BP, Kerr D, Bevier WC, Brazg RL, et al. Investigation of the Accuracy of 18 Marketed Blood Glucose Monitors. Diabetes Care. 2018 Aug;41(8):1681-8. DOI: 10.2337/dc17-1960

20. Rebel A, Rice MA, Fahy BG. Accuracy of point-of-care glucose measurements. J Diabetes Sci Technol. 2012 Mar 1;6(2):396-411. DOI: 10.1177/193229681200600228

21. American Diabetes Association. Diabetes Care in the Hospital: Standards of Medical Care in Diabetes-2018. Diabetes Care. 2018 Jan;41(Suppl 1):S144-S51. DOI: $10.2337 / \mathrm{dc} 18-\mathrm{S} 014$

22. Joseph JI, Hipszer B, Mraovic B, Chervoneva I, Joseph M, Grunwald Z. Clinical need for continuous glucose monitoring in the hospital. J Diabetes Sci Technol. 2009 Nov 1;3(6):1309-18. DOI: 10.1177/193229680900300611

23. Bailey T, Bode BW, Christiansen MP, Klaff LJ, Alva S. The Performance and Usability of a Factory-Calibrated Flash Glucose Monitoring System. Diabetes Technol Ther. 2015 Nov;17(11):787-94. DOI: 10.1089/ dia.2014.0378

24. Food and Drug Administration. iPro2 Continuous Glucose Monitoring (CGM) System 2016. https:/www. accessdata.fda.gov/cdrh_docs/pdf15/P150029B.pdf

25. Food and Drug Administration. Freestyle Libre Pro Flash Glucose Monitoring System 2016. https:/www. accessdata.fda.gov/cdrh_docs/pdf15/P150021B.pdf

26. Nakamura K, Balo A. The Accuracy and Efficacy of the Dexcom G4 Platinum Continuous Glucose Monitoring System. J Diabetes Sci Technol. 2015 Mar 23;9(5):1021-6. DOI: 10.1177/1932296815577812

27. Food and Drug Administration Advisory Panel Votes to Recommend Non-Adjunctive Use of Dexcom G5 Mobile CGM. Diabetes Technol Ther. 2016 Aug;18(8):5126. DOI: 10.1089/dia.2016.07252.mr

28. Gomez AM, Henao Carrillo DC, Munoz Velandia OM. Devices for continuous monitoring of glucose: update in technology. Med Devices (Auckl). 2017 10:215-24. DOI: $10.2147 /$ MDER.S110121

29. Thabit H, Leelarathna L, Wilinska ME, Elleri D, Allen JM, Lubina-Solomon A, et al. Accuracy of Continuous Glucose Monitoring During Three Closed-Loop
Home Studies Under Free-Living Conditions. Diabetes Technol Ther. 2015 Nov;17(11):801-7. DOI: 10.1089/ dia.2015.0062

30. Boscari F, Galasso S, Acciaroli G, Facchinetti A, Marescotti MC, Avogaro A, et al. Head-to-head comparison of the accuracy of Abbott FreeStyle Libre and Dexcom G5 mobile. Nutr Metab Cardiovasc Dis. 2018 Apr;28(4):425-7. DOI: 10.1016/j.numecd.2018.01.003

31. Stone MP, Agrawal P, Chen X, Liu M, Shin J, Cordero TL, et al. Retrospective Analysis of 3-Month Real-World Glucose Data After the MiniMed 670G System Commercial Launch. Diabetes Technol Ther. 2018 Oct;20(10):689-92. DOI: 10.1089/dia.2018.0202

32. Foster NC, Miller KM, Tamborlane WV, Bergenstal RM, Beck RW, Network TDEC. Continuous Glucose Monitoring in Patients With Type 1 Diabetes Using Insulin Injections. Diabetes Care. 2016 Jun;39(6):e81-2. DOI: $10.2337 / \mathrm{dc} 16-0207$

33. Beck RW, Riddlesworth T, Ruedy K, Ahmann A, Bergenstal R, Haller S, et al. Effect of Continuous Glucose Monitoring on Glycemic Control in Adults With Type 1 Diabetes Using Insulin Injections: The DIAMOND Randomized Clinical Trial. JAMA. 2017 Jan 24;317(4):371-8. DOI: 10.1001/jama.2016.19975

34. Lind M, Polonsky W, Hirsch IB, Heise T, Bolinder J, Dahlqvist S, et al. Continuous Glucose Monitoring vs Conventional Therapy for Glycemic Control in Adults With Type 1 Diabetes Treated With Multiple Daily Insulin Injections: The GOLD Randomized Clinical Trial. JAMA. 2017 Jan 24;317(4):379-87. DOI: 10.1001/ jama.2016.19976

35. Jamiolkowska M, Jamiolkowska I, Luczynski W, Tolwinska J, Bossowski A, Glowinska Olszewska B. Impact of Real-Time Continuous Glucose Monitoring Use on Glucose Variability and Endothelial Function in Adolescents with Type 1 Diabetes: New Technology--New Possibility to Decrease Cardiovascular Risk? J Diabetes Res. 2016 2016:4385312.

36. Gomez AM, Alfonso-Cristancho R, Orozco JJ, Lynch PM, Prieto D, Saunders R, et al. Clinical and economic benefits of integrated pump/CGM technology therapy in patients with type 1 diabetes in Colombia. Endocrinol Nutr. 2016 Nov;63(9):466-74. DOI: 10.1016/j.endonu.2016.05.011

37. Bolinder J, Antuna R, Geelhoed-Duijvestijn P, Kroger J, Weitgasser R. Novel glucose-sensing technology and hypoglycaemia in type 1 diabetes: a multicentre, 
non-masked, randomised controlled trial. Lancet. 2016 Nov 5;388(10057):2254-63. DOI: 10.1016/S01406736(16)31535-5

38. Danne T, Nimri R, Battelino T, Bergenstal RM, Close $\mathrm{KL}$, DeVries JH, et al. International Consensus on Use of Continuous Glucose Monitoring. Diabetes Care. 2017 Dec;40(12):1631-40. DOI: 10.2337/dc17-1600

39. Adolfsson P, Parkin CG, Thomas A, Krinelke LG. Selecting the Appropriate Continuous Glucose Monitoring System - a Practical Approach. Eur Endocrinol. 2018 Apr;14(1):24-9. DOI: 10.17925/EE.2018.14.1.24

40. DuBose JJ, Inaba K, Branco BC, Barmparas G, Lam L, Teixeira PG, et al. Discrepancies between capillary glucose measurements and traditional laboratory assessments in both shock and non-shock states after trauma. J Surg Res. 2012 Dec;178(2):820-6. DOI: 10.1016/j. jss.2012.04.003

41. Ellis MF, Benjamin K, Cornell M, Decker K, Farrell D, McGugan L, et al. Suitability of capillary blood glucose analysis in patients receiving vasopressors. Am J Crit Care. 2013 Sep;22(5):423-9. DOI: 10.4037/ ajec2013692

42. Boom DT, Sechterberger MK, Rijkenberg S, Kreder S, Bosman RJ, Wester JP, et al. Insulin treatment guided by subcutaneous continuous glucose monitoring compared to frequent point-of-care measurement in critically ill patients: a randomized controlled trial. Crit Care. 2014 Aug 20;18(4):453. DOI: 10.1186/s13054-0140453-9

43. Bochicchio GV, Hipszer BR, Magee MF, Bergenstal RM, Furnary AP, Gulino AM, et al. Multicenter Observational Study of the First-Generation Intravenous Blood Glucose Monitoring System in Hospitalized Patients. J Diabetes Sci Technol. 2015 Jul;9(4):739-50. DOI: 10.1177/1932296815587939

44. Yamashita K, Okabayashi T, Yokoyama T, Yatabe T, Maeda H, Manabe M, et al. Accuracy and reliability of continuous blood glucose monitor in post-surgical patients. Acta Anaesthesiol Scand. 2009 Jan;53(1):66-71. DOI: 10.1111/j.1399-6576.2008.01799.x

45. Munekage M, Yatabe T, Sakaguchi M, Kitagawa H, Tamura T, Namikawa T, et al. Comparison of subcutaneous and intravenous continuous glucose monitoring accuracy in an operating room and an intensive care unit. J Artif Organs. 2016 Jun;19(2):159-66. DOI: 10.1007/ s10047-015-0877-2

46. Shephard M, Shephard A, McAteer B, Regnier T, Barancek K. Results from 15years of quality surveillance for a National Indigenous Point-of-Care Testing Program for diabetes. Clin Biochem. 2017 Dec;50(18):1159-63. DOI: 10.1016/j.clinbiochem.2017.07.007

47. Biethman RK, Pandarakalam C, Garcia MN, Whitener S, Hildebolt CF. Screening for Diabetes in a Dental School Clinic to Assess Interprofessional Communication Between Physicians and Dental Students. J Dent Educ. 2017 Sep;81(9):1062-7. DOI: 10.21815/ JDE.017.059

48. Whitley HP, Hanson C, Parton JM. Systematic Diabetes Screening Using Point-of-Care HbA1c Testing Facilitates Identification of Prediabetes. Ann Fam Med. 2017 Mar;15(2):162-4. DOI: 10.1370/afm.2035

49. Paknikar S, Sarmah R, Sivaganeshan L, Welke A, Rizzo A, Larson $\mathrm{K}$, et al. Long-Term Performance of Point-of-Care Hemoglobin A1c Assays. J Diabetes Sci Technol. 2016 Nov;10(6):1308-15. DOI: 10.1177/1932296816645362

50. Whitley HP, Yong EV, Rasinen C. Selecting an A1C Point-of-Care Instrument. Diabetes Spectr. 2015 Aug;28(3):201-8. DOI: 10.2337/diaspect.28.3.201

51. National Glycohemoglobin Standardization Program homepage http://www.ngsp.org.

52. Ferenczi A, Reddy K, Lorber DL. Effect of immediate hemoglobin A1c results on treatment decisions in office practice. Endocr Pract. 2001 Mar-Apr;7(2):85-8. DOI: 10.4158/EP.7.2.85

53. Zhou R, Wang W, Song ZX, Tong Q, Wang QT. Evaluation of a new hemoglobin A1c analyzer for pointof-care testing. J Clin Lab Anal. 2018 Jan; 32(1) DOI: $10.1002 /$ jcla. 22172

54. Bergenstal RM, Gal RL, Connor CG, Gubitosi-Klug R, Kruger D, Olson BA, et al. Racial Differences in the Relationship of Glucose Concentrations and Hemoglobin A1c Levels. Ann Intern Med. 2017 Jul 18;167(2):95102. DOI: $10.7326 / \mathrm{M} 16-2596$

55. Lim S, Yu HJ, Lee S, Park H, Kwon MJ, Woo HY. Evaluation of the URiSCAN 2 ACR Strip to estimate the urine albumin/creatinine ratios. J Clin Lab Anal. 2017 Mar;32(3):1-6. 